\title{
PEMB ENTUKAN DAN PENGUKURAN KINERJA PORTOFOLIO EFISIEN DENGAN METODE CONSTANT CORRELATION MODEL MENGGUNAKAN GUI MATLAB (Studi Kasus: Kelompok Saham pada Indeks JII, LQ45, dan INFOBANK15)

\author{
Muhammad Zidan Eka Atmaja ${ }^{1 *}$, Alan Prahutama ${ }^{2}$, Dwi Ispriyanti ${ }^{3}$ \\ 1,2,3 Departemen Statistika, Fakultas Sains dan Matematika, Universitas Diponegoro \\ e-mail: zidanmuhammad10@yahoo.com
}

\begin{abstract}
Investment is an important part of fin ancial management that is widely known by the public. One example of an investment is a stock, stock is favored by investors because many of companies issue stock investment. inves tors goal from investment are to get funds that have been invested. Besides adv antage, investors also have to face risks that can befall on him. Risk in investment can be minimized by diversification, for example by forming a portfolio. A good portfolio is an efficient portfolio, which is a portfolio that has a high rate of retum with minimal risk. One of the way to to form an efficient portfolio is the Constant Correlation Model (CCM) method. The CCM method focuses on Excess return to Standard Deviation (ERS) and correlation between paired stocks. And to measure the portfolio formed can be measured by the Sharpe Ratio. GUI MATLAB program was formed to make it easier to find portfolio from the CCM method. This research uses stock data on the stock indexJII, LQ45, and INFOBANK15 with interestrate of SBI period 2October 2017-30 December 2019. Based on the results and discussion with manual calculations and GUI MATLAB, it can be concluded that percentage of weight, expected return, risk, and Sharpe index produce the same numbers.
\end{abstract}

Keywords: Stock, Efficient Portfolio, Constant Correlation Model, Sharpe Ratio

\section{PENDAHULUAN}

Di zaman ini investasi sudah sangat berkembang di masyarakat Indonesia. Menurut Halim (2003) investasi merupakan penempatan sejumlah dana pada saat ini dengan harapan untuk memperoleh keuntungan di masa mendatang. Salah satu instrumen dari investasi adalah saham, Anoraga dan Pakarti (2001) menjelaskan saham dapat didefinisikan sebagai surat berharga sebagai bukti penyertaan atau pemilikan individu maupun institusi dalam suatu perusahaan.

Investor akan selalu berusahan untuk menghindari risiko yang memungkinkan terjadi pada dirinya. Adapun cara untuk meminimalisir risiko yaitu menggabungkan sahamsahamnya menjadi portofolio. Menurut (Hadi 2013) portofolio merupakan kumpulan dari instrumen investasi yang dibentuk untuk memenuhi satu sasaran umum investasi. Portofolio memungkinkan investor agar aset yang dipunya tidak habis seketika bagaimana saham dibentuk untuk menghasilkan portofolio yang memiliki return tinggi sehingga menjadi portofolio yang efisien.

Constant Correlation model (CCM) adalah salah satu metode yang mulai dikembangkan oleh Elton dan Gruber sejak tahun 1987. Menurut Elton dan Gurber (1991) CCM mengasumsikan bahwa korelasi antar saham konstan. Pada suatu kelompok indeks saham terdapat beberapa saham yang masuk, dan pada indeks harga saham tersebut dianggap bahwa saham-saham tersebut saling berkorelasi. Metode CCM ini dipilih sebagai teknik untuk memperoleh portofolio efisien karena investor beranggapan bahwa naik turunnya harga saham dipengaruhi oleh harga saham yang lainnya. Terdapat beberapa penelitian terdahulu dengan metode ini, pertama dari Juniyanto (2016) mengangkat Constant Correlation Model dengan studi kasus pada indeks saham JII. Penelitian ini menghasilkan tujuh dari sembilan saham masuk pada portofolio optimal dengan nilai harapan pengembalian sebesar 3,40\%. Penelitian kedua oleh Sucitra et al. (2017) mengangkat penelitian Constant Correlation Model dan penilaian kinerja Sharpe dan Treynor pada JII. Hasil dari penelitian ini mendapatkan 5 portofolio, terdapat satu portofolio yang kurang baik 
berdasarkan kinerja Sharpe dan berdasarkan kinerja Treynor seluruhnya baik. Perbedaan penelitian yang akan diteliti yaitu pada studi kasus yang diambil meliputi tiga indeks saham dan penambahkan program GUI MATLAB untuk memudahkan dalam pencarian portofolio efisien mulai dari emiten, bobot, expected return, risiko, dan Rasio Sharpe.

\section{TINJAUAN PUSTAKA}

\subsection{Investasi}

Herlianto (2013) menjelaskan investasi pada dasarnya merupakan penempatan sejumlah dana pada saatini dengan tujuan untuk memperoleh sejumlah keuntungan di masa yang akan datang. Salah satu bagian dari investasi yaitu adalah saham. Saham dapat didefinisikan sebagai tanda atau kepemilikan seseorang atau badan dalam suatu perusahaan atau perseroan terbatas. Wujud saham adalah, selembar kertas yang menerangkan bahwa pemilik kertas tersebut adalah pemilik perusahaan yang menerbitkan surat berharga tersebut (Darmadji dan Fakhruddin, 2001).

BEI memiliki kumpulan saham-saham yang yang dapat dikelompokkan dalam satu indeks harga saham. Indeks harga saham adalah indikator yang menunjukkan pergerakan harga saham. Indeks harga saham merupakan tren pasar yaitu menggambarkan kondisi pasar suatu saat apakah pasar sedang aktif atau lesu. (Hadi, 2013). Diantaranya Indeks LQ45 adalah indeks yang mengukur kinerja harga dari 45 saham yang memiliki likuiditas tinggi dan nilai kapitalis pasar yang besar. Kedua indeks INFOBANK15 adalah indeks yang mengukur kinerja harga dari 15 saham perbankan yang memiliki faktor fundamental yang baik dan likuiditas perdagangan yang tinggi. Ketiga adalah JII Halim (2003) menjelaskan Jakarta Islamic Index (JII) adalah indeks saham yang memenuhi kriteria investasi dalam syariat Islam. Saham-saham yang masuk dalam JII adalah emiten yang kegiatan usahanya tidak bertentangan dengan syariat Islam.

Portofolio merupakan kumpulan dari instrumen investasi yang dibentuk untuk memenuhi suatu sasaran umum investasi. Sasaran dari suatu portofolio investasi tentunya sangat tergantung pada individu masing-masing investor. Portofolio yang efisien adalah melakukan investasi dalam saham atau gabungan saham yang memberikan keuntungan yang diharapkan tinggi (expected return) dengan tingkat risiko tertentu (expected risk) atau yang bersedia investor tanggung (Hadi, 2013).

\subsection{Constant Correlation Model}

Constant Correlation Model (CCM) mulai dikembangkan oleh Elton dan Gruber. Menurut Elton dan Gruber (1991) salah satu cara untuk mendapatkan portofolio yang baik adalah dengan menggunakan koefisien korelasi. Elton dan Gruber mengasumsikan Constant Correlation Model bahwa korelasi setiap pasang saham sama. Prosedur untuk penentuan portofolio dengan menggunakan CCM yang membedakan dengan teknik lain yaitu pada perhitungan Excess return to Standard Deviation (ERS). Pembentukan portofolio menggunakan metode CCM terdapat dua kondisi yaitu short sales diperbolehkan dan short sales tidak diperbolehkan. Penelitian dengan metode CCM yang akan diteliti, kondisi yang digunakan adalah short sales tidak diperbolehkan. Short sales adalah peminjaman saham dengan menjual saham tersebut dan membelinya kembali pada kondisi saham dibawah harga penjualan.

\subsection{Return dan Expected Return}


Samsul (2006) menjelaskan return saham adalah pendapatan yang dinyatakan dalam persentase dari modal awal investasi. Hartono (2014) return saham dirumuskan sebagai berikut:

Keterangan simbol:

$$
R_{i, t}=\frac{P_{t}-P_{t-1}}{P_{t-1}}
$$

$\mathrm{R}_{\mathrm{i}, \mathrm{t}}=$ Actual return dari saham ke-i pada waktu ke- $\mathrm{t}$

$\mathrm{P}_{\mathrm{t}} \quad=$ Closing Price saham pada waktu ke- $\mathrm{t}$

$\mathrm{P}_{\mathrm{t}-1}=$ Closing Price saham pada waktu ke-t- 1

Menurut Halim (2015) expected return secara sederhana adalah rata-rata tertimbang dari berbagai return historis.

Keterangan simbol:

$$
\mathrm{E}\left(\mathrm{R}_{\mathrm{i}}\right)=\frac{\sum_{\mathrm{t}=1}^{\mathrm{n}} \mathrm{R}_{\mathrm{it}}}{\mathrm{n}}
$$

$\mathrm{E}(\mathrm{R})_{\mathrm{i}}=$ Expected return dari saham ke- $\mathrm{i}$

$\mathrm{R}_{\mathrm{i}, \mathrm{t}} \quad=$ Actual return dari saham ke-i pada waktu ke- $\mathrm{t}$

$\mathrm{n} \quad=$ Return yang terjadi pada banyaknya pengamatan

\subsection{Risiko Saham}

Halim (2015) menjelaskan dalam konteks manajemen investasi, risiko merupakan penyimpangan antara tingkat pengembalian yang diharapkan (expected return) dengan tingkat pengembalian yang dicapai secara nyata (actual return)

Keterangan simbol:

$$
\mathrm{S}_{\mathrm{i}}=\sqrt{\frac{\sum_{\mathrm{t}=1}^{\mathrm{n}}\left\{\mathrm{R}_{\mathrm{it}}-\left(\mathrm{E}\left(\mathrm{R}_{\mathrm{i}}\right)\right\}^{2}\right.}{\mathrm{n}-1}}
$$

$\mathrm{S}_{\mathrm{i}} \quad=$ Standard Deviation dari saham ke-i

$\mathrm{R}_{\mathrm{i}, \mathrm{t}}=$ Actual return dari saham $\mathrm{ke}=\mathrm{i}$ pada waktu ke- $\mathrm{t}$

$\mathrm{E}\left(\mathrm{R}_{\mathrm{i}}\right)=$ Expected return dari saham ke-i

$\mathrm{n} \quad=$ Banyak pengamatan

\subsection{Excess Return to Standard Deviation}

Apabila Constant Correlation Model dapat mendeskripsikan pergerakan antar saham, maka seluruh saham dapat diurutkan dari Excess Return to Standard deviation (Elton dan Gruber, 1991). Menurut Tandelilin (2001) risk free rate $\left(\mathrm{R}_{\mathrm{f}}\right)$ dicari dan dihitung dari data Suku Bunga SBI. Risk free rate ditentukan oleh peneliti dapat menggunakan data SBI pada periode saat ini, pada awal periode penelitian, dan dengan rata-rata SBI sepanjang periode.

Keterangan simbol:

$$
\mathrm{R}_{\mathrm{f}}=\frac{\sum_{\mathrm{q}=1}^{\mathrm{P}} \mathrm{SBI}_{\mathrm{q}}}{\mathrm{P}}
$$

$\mathrm{R}_{\mathrm{f}} \quad=$ Risk free Rate (bunga bebas risiko)

$\mathrm{p} \quad=$ Banyaknya periode pengamatan SBI

$\mathrm{SBI}_{\mathrm{q}}=$ Sertifikat Bank Indonesia periode ke-q (SBI dikeluarkan tiap bulan)

Keterangan simbol:

$$
\mathrm{ERS}_{\mathrm{i}}=\frac{\left(\mathrm{E}\left(\mathrm{R}_{\mathrm{i}}\right)-\mathrm{R}_{\mathrm{f}}\right)}{\mathrm{S}_{\mathrm{i}}}
$$

ERS $_{\mathrm{i}}=$ Excess Return to Standard Deviation saham ke-i 
$\mathrm{R}_{\mathrm{f}} \quad=$ Risk free Rate (bunga bebas risiko)

$\mathrm{E}\left(\mathrm{R}_{\mathrm{i}}\right)=$ Expected return saham ke- $\mathrm{i}$

$\mathrm{S}_{\mathrm{i}} \quad=$ Standard Deviation saham ke- $\mathrm{i}$

\subsection{Korelasi}

Koefisien korelasi $\rho$ digunakan untuk mengetahui kuat atau tidaknya hubungan antara variabel-variabel. Nilai koefisien korelasi berada antara 1 dan $-1(-1 \leq \rho \leq 1)$. Berikut adalah koefisien korelasi Pearson (Pearson's productmomentcoefficient of correlation). Penentuan koefisien dengan menggunakan Pearson's product moment coefficient of correlation menggunakan rumus sebagai berikut (Sugiyono, 2013).

Keterangan simbol:

$$
\rho_{\mathrm{ij}}=\frac{\mathrm{n} \sum_{\mathrm{t}=1}^{\mathrm{n}} \mathrm{R}_{\mathrm{it}} \mathrm{R}_{\mathrm{jt}}-\sum_{\mathrm{t}=1}^{\mathrm{n}} \mathrm{R}_{\mathrm{it}} \sum_{\mathrm{t}=1}^{\mathrm{n}} \mathrm{R}_{\mathrm{jt}}}{\left\{\sqrt{\mathrm{n} \sum_{\mathrm{t}=1}^{\mathrm{n}} \mathrm{R}_{\mathrm{it}}^{2}-\left(\sum_{\mathrm{t}=1}^{\mathrm{n}} \mathrm{R}_{\mathrm{it}}\right)^{2}}\right\}\left\{\mathrm{n} \sqrt{\sum_{\mathrm{t}=1}^{\mathrm{n}} \mathrm{R}_{\mathrm{it}}^{2}-\left(\sum_{\mathrm{t}=1}^{\mathrm{n}} \mathrm{R}_{\mathrm{jt}}\right)^{2}}\right\}}
$$

$\rho_{\mathrm{ij}}=$ Korelasi saham $\mathrm{i}$ dengan saham $\mathrm{j}$ untuk $\mathrm{i \neq j}$

$\mathrm{n} \quad=$ Banyak pengamatan

$\mathrm{R}_{\mathrm{it}}=$ Return saham i waktu ke-t

$\mathrm{R}_{\mathrm{jt}}=$ Return saham $\mathrm{j}$ waktu ke-t

Menurut Frade (2017) berikut ini adalah rumus sebagai pairwise comparison (perbandingan berpasangan) untuk korelasi antar return saham.

Untuk $\mathrm{i}=1,2, \ldots, \mathrm{K}, \mathrm{j}=1,2, \ldots, \mathrm{K}$ Dengan $\mathrm{i}>\mathrm{j}$

$$
\rho *=\frac{\sum_{\mathrm{i}=1}^{\mathrm{K}} \sum_{\mathrm{j}=1}^{\mathrm{K}} \rho_{\mathrm{ij}}}{\frac{\mathrm{K} *(\mathrm{~K}-1)}{2}}
$$

Keterangan simbol:

$\rho_{\mathrm{ij}}=$ Korelasi saham $\mathrm{i}$ dengan saham $\mathrm{j}$ untuk $\mathrm{i \neq j}$

$\rho^{*}=$ Rata-rata korelasi

$K=$ Banyaknya saham

\subsection{Cut-Off Rate}

Menghitung nilai cut-off rate dengan menggunakan data yang telah didapat

Keterangan simbol:

$$
\mathrm{C}_{\mathrm{i}^{*}}=\frac{\rho^{*}}{1-\rho^{*}+\left(\rho^{*} \mathrm{i}^{*}\right)} \sum_{\mathrm{i}^{*}=1}^{\mathrm{K}} \operatorname{ERS}_{\mathrm{i}^{*}}
$$

$\mathrm{i}^{*} \quad=$ Urutan saham dengan ERS tertinggi sampai ERS terendah

$\mathrm{C}_{\mathrm{i}^{*}} \quad=$ Nilai Cut-off saham ke-i*

$\rho^{*} \quad=$ Rata-rata korelasi

ERS $_{\mathrm{i}^{*}}=$ Excess Return to Standard Deviation ke-i yang sudah diurutkan

$\mathrm{K} \quad$ = Banyaknya saham

Nilai $\mathrm{C}_{\mathrm{i}}$ terbesar akan dijadikan Cut-off Rate dan akan dibandingkan dengan nilai ERS masing-masing saham apabila nilai ERS kurang dari Cut-off Rate akan dikeluarkan dari kandidat portofolio.

\subsection{Persentase Bobot}


Menurut Elton dan Gruber (1991) melakukan optimalisasi investasi untuk beberapa saham adalah dengan melakukan persentase pembobotan terhadap saham-saham yang masuk dalam portofolio.

$$
\mathrm{Z}_{\mathrm{i}^{*}}=\frac{1}{\left(1-\rho^{*}\right) \mathrm{S}_{\mathrm{i}}}\left[\mathrm{ERS}_{\mathrm{i}^{*}}-\mathrm{C}^{*}\right]
$$

Keterangan simbol:

$\mathrm{Z}_{\mathrm{i}^{*}} \quad=$ Investasi relatif saham ke-i*

$\mathrm{C}^{*} \quad=$ Cut-off rate

$\rho^{*} \quad=$ Rata-rata korelasi

ERS $_{\mathrm{i}^{*}} \quad=$ Excess Return to Standard Deviation ke-i yang sudah diurutkan

Maka:

$$
\mathrm{X}_{\mathrm{i}^{*}}=\frac{\mathrm{Z}_{\mathrm{i}^{*}}}{\sum_{\mathrm{i}^{*}=1}^{\mathrm{g}} \mathrm{Z}_{\mathrm{i}^{*}}}
$$

Keterangan simbol:

$\mathrm{Z}_{\mathrm{i}^{*}} \quad=$ Investasi relatif untuk saham ke-i*

$\mathrm{X}_{\mathrm{i}^{*}} \quad=$ Persentase bobot untuk tiap-tiap saham-i*

$\mathrm{g}=$ Banyak saham yang memiliki ERS lebih dari nilai Cut-off rate

\subsection{Expected Return dan Risiko Portofolio}

Menurut Fabozzi (1999) pengembalian dari suatu portofolio aktiva sepanjang periode waktu tertentu secara langsung dapat diperhitungkan sebagai berikut:

$$
E\left(R_{p}\right)=\sum_{g=1}^{G} X_{g} E\left(R_{g}\right)
$$

Keterangan simbol:

$\mathrm{E}\left(\mathrm{R}_{\mathrm{p}}\right)=$ Expected Return portofolio

$\mathrm{X}_{\mathrm{g}} \quad=$ Persentase bobot untuk tiap-tiap saham ke-g

$\mathrm{E}\left(\mathrm{R}_{\mathrm{g}}\right)=$ Expected Return saham ke-g

$\mathrm{G}=$ Jumlah saham pada portofolio

Menurut Bodie et al (2014) portofolio dari aset berisiko relatif mudah dianalisis, dan menggambarkan prinsip pertimbangan yang diguakan pada portofolio berbagai aset.

$$
S_{P}^{2}=\sum_{g=1}^{G} X_{g}^{2} S_{g}^{2}+\sum_{g=1}^{G} \sum_{h=1}^{G} X_{g} X_{h} \rho_{g h} S_{g} S_{h} \text { untuk } g \neq h
$$

Keterangan simbol:

$\mathrm{S}_{\mathrm{P}}^{2}=$ Variance Portofolio

$\mathrm{X}_{\mathrm{g}}^{2}=$ Persentase Bobot kuadrat saham ke-g

$\mathrm{S}_{\mathrm{g}}^{2}=$ Variance saham ke-g

$\mathrm{X}_{\mathrm{g}}=$ Persentase Bobot saham ke-g

$\mathrm{X}_{\mathrm{h}}=$ Persentase Bobot saham ke-h

$\rho_{\text {gh }}=$ Korelasi saham g dengan saham $\mathrm{h}$

$\mathrm{S}_{\mathrm{g}}=$ Standard deviation saham ke-g

$\mathrm{S}_{\mathrm{h}}=$ Standard deviation saham ke-h

\subsection{Kinerja Portofolio}


Jones (2014) menyatakan bahwa pengukuran kinerja merupakan bagian penting dari proses pengukuran investasi, pengukuran kinerja memungkinkan investor untuk menentukan keberhasilannya, dan memungkinkan investor mengevaluasi risiko yang diambil dan melakukan perbaikan dalam proses pembentukan portofolio, Salah satu cara mengukur kinerja yaitu dengan menggunakan indeks Sharpe (Tandelilin, 2001).

Keterangan simbol:

$$
I_{s}=\frac{\left(E\left(R_{p}\right)-R_{f}\right)}{S_{p}}
$$

$\mathrm{I}_{\mathrm{S}} \quad=$ Rasio sharpe portofolio

$\mathrm{E}\left(\mathrm{R}_{\mathrm{p}}\right)=$ Expected Return portofolio

$\mathrm{R}_{\mathrm{f}} \quad=$ Risk Free Rate (Bunga Bebas Risiko)

$\mathrm{S}_{\mathrm{p}} \quad=$ Standard Deviation portofolio

\subsection{GUI MATLAB}

MATLAB merupakan perangkat lunak yang digunakan untuk pemograman, analisis, serta komputasi teknis dan matematis berbasis matriks MATLAB juga memiliki keunggulan umum lainnya, seperti analisis dan eksplorasi data, pengembangan algoritma, pemodelan dan simulasi, visualisasi plot dalam bentuk 2D dan 3D, hingga pengembangan aplikasi antar muka grafis (Tjolleng, 2017). Salah satu fitur dalam Matlab adalah GUI, GUI digunakan untuk membuat program yang diinginkan oleh peneliti

\section{METODE PENELITIAN}

\subsection{Sumber Data dan Variabel Data}

Jenis data yang digunakan dalam tugas akhir ini adalah data sekuder yaitu data yang diambil melalui perantara pihak lain yang telah melakukan pengumpulan data. Dalam penelitian ini menggunakan data yang diambil dari beberapa website, yaitu Yahoo Finance www.finance.yahoo.com, Bank Indonesia www.bi.go.id dan Bursa Efek Indonesia www.idx.co.id. Dengan Variabel pada indeks saham JII, LQ45, dan INFOBANK15 pada periode Oktober 2017-Desember 2019 yang tetap bertahan pada periode tersebut.

\subsection{Tahapan Analisis}

1. Memilih saham dalam indeks JII, LQ45, dan INFOBANK15 pada periode Oktober 2017-Desember 2019.

2. Mencari nilai closing price harian masing-masing saham dan SBI pada periode 2 Oktober 2017-30 Desember 2019.

3. Analisis deskriptif

4. Menghitung nilai Return masing-masing saham. nilai Expected Return dan Standard Deviation dari tiap saham tunggal.

5. Menentukan nilai Risk Free Rate dan Menghitung nilai Excess Return to Standar Deviation (ERS) dan mengurutkan ERS terbesar sampai ERS terkecil serta mereduksi saham ERS yang bernilai negatif.

6. Menghitung nilai korelasi return antar dua saham untuk semua saham masuk dan menghitung rata-rata dari korelasi tersebut.

7. Menghitung nilai Cut-off untuk setiap saham, dan memilih nilai Cut-off tertinggi untuk dijadikan Cut off Rate.

8. Membandingkan Nilai ERS masing-masing saham dengan Cut-off rate, bila ERS kurang dari nilai Cut-off rate maka saham tersebut akan dikeluarkan. 
9. Menghitung investasi relatif $\left(Z_{i}^{*}\right)$ per saham kemudian total dari keseluruhan $Z_{i}^{*}$, dan menghitung persentase bobot saham dengan cara membagi dari nilai $Z_{i^{*}}$ dengan total $\mathrm{Z}_{\mathrm{i}}^{*}$.

10. Menghitung return, risiko, dan kinerja dari portofolio.

\section{HASIL DAN PEMBAHASAN \\ 4.1 Analisis Deskriptif}

Diketahui dari tiga indeks saham yaitu JII, LQ45, dan INFOBANK15 terdapat 39 saham. Berdasarkan perhitungan dari nilai maksimum dan minimum untuk tiap emiten selama 2 tahun memiliki nilai rentang yang cukup besar dengan nilai rentang closing price terbesar bernilai 45.175 untuk emiten GGRM dan nilai rentang terendah bernilai untuk emiten SRIL 160. Nilai closing price tertinggi dan terendah terdapat pada indeks harga saham LQ45, dapat dengan nilai closing price tertinggi oleh GGRM dengan sebesar 94.400 dan SRIL sebesar 404.

\subsection{Pembentukan Portofolio}

- Return, Expected Return dan Standard Deviation

$$
\begin{gathered}
R_{I N C O, 1}=\frac{(2.750-2.600)}{2500}=0,057692 \\
\sigma_{\mathrm{INCO}}=\sqrt{\frac{\{(0,057592-0,000942)+\cdots+(0,031161-0,000942)\}^{2}}{581}} \\
=0,027094
\end{gathered}
$$

Dari Perhitungan 583 data Closing Price didapatkan sebanyak 582 return. Nilai Expected Return dan Risiko sebanyak 18 untuk JII, 33 LQ45 dan 10 INFOBANK15.

\section{- Risk Free Rate dan Excess Return to Standard Deviation}

Risk free rate membutuhkan nilai SBI dan dari penelitian ini terdapat 27 data SBI.

$$
\mathrm{R}_{\mathrm{f}(\text { harian })}=\frac{(4,5 \%+\cdots+5 \%)}{(27)(360)}=0,0145576 \%
$$

ERS (Excess Return to Standard Deviation) membutuhkan nilai expected return, standard deviation, dan risk free rate.

$$
\mathrm{ERS}_{\text {INCO }}=\frac{(0,000942-0,000145576)}{0,027094}=0,029386
$$

Dari perhitungan ERS yang sudah dilakukan terdapat sebanyak 5 ERS yang bernilai positif dan 13 ERS yang bernilai negatif untuk indeks JII. Terdapat 14 ERS bernilai positif dan 19 ERS bernilai negatif untuk indeks LQ45. Indeks INFOBANK15 memiliki 5 ERS bernilai positif dan 5 ERS bernilai negatif. Seluruh ERS bernilai negatif dari ketiga indeks dikeluarkan dari kandidat portofolio dan untuk ERS positif diurutkan berdasarkan ERS tertinggi sampai terendah.

\section{- Korelasi}

Setelah dilakukan perhitungan ERS untuk tiap ERS bernilai positif dihitung korelasi antar tiap saham.

$$
\left.\rho_{(I N C O)(P T B A)}=\frac{582 \sum_{t=1}^{582} R_{I N C O(t)} R_{P T B A(t)}-\sum_{t=1}^{582} R_{I N C O(t)} \sum_{t=1}^{582} R_{P T B A(t)}}{\left.\left\{\sqrt{582 \sum_{t=1}^{582} R_{I N C O(t)^{2}}-\left(\sum_{t=1}^{582} R_{I N C O}(t)\right.}\right)^{2}\right\}\left\{582 \sqrt{\sum_{t=1}^{582} R_{P T B A(t)}-\left(\sum_{t=1}^{582} R_{P T B A t}\right)^{2}}\right.}\right\}
$$


Dari ketiga saham didapatkan untuk indeks JII memiliki 10 korelasi, untuk LQ45 memiliki 91 korelasi dan untuk INFOBANK15 memiliki 10 korelasi.

1. Rata-rata Korelasi Indeks JII

$$
\rho^{*}=\frac{(0,203081+0,655843+\cdots+0,263542+0,139539)}{10}=0,212333
$$

2. Rata-rata Korelasi Indeks LQ45

$$
\rho^{*}=\frac{(0,158593+0,218289+\cdots+0,338938+0,380304)}{91}=0,237981
$$

3. Rata-rata Korelasi Indeks INFOBANK15

$$
\rho^{*}=\frac{(0,0444349+0,073685+\cdots+0,0110419+0,629868)}{10}=0,357228
$$

\section{- Cut-off Rate}

Selanjutnya setelah menghitung nilai rata-rata korelasi maka akan dihitung nilai cut-off untuk tiap-tiap emiten. Perhitungan cut-off dibutuhkan nilai ERS dan rata-rata korelasi.

$$
C_{I N C O}=\frac{0,212333}{1-0,212333+(1(0,212333))}(0,029386)=0,006240
$$

Dari indeks JII mendapatkan nilai $\mathrm{Ci}$ terbesar pada saham ICBP dengan nilai $(0,0013633)$, untuk indeks LQ45 pada saham BBRI dengan nilai $(0,031797)$ dan untuk indeks INFOBANK15 pada saham BBRI dengan nilai $(0,026826)$. Kemudian ERS tiap sekuritas pada di tiap indeks dibandingkan dengan nilai Cut-off Rate masing-masing. Diketahui indeks JII terdapat empat saham. Indeks LQ45 tiga saham, dam indeks INFOBANK15 dua saham yang memiliki nilai lebih dari nilai Cut-off Rate masing-masing indeks. Saham-saham inilah yang akan dijadikan bagian portofolio untuk tiap indeksnya.

\section{- Investasi Relatif dan Persentase Bobot}

Selanjutnya dilakukan perhitungan investasi relatif terlebih dahulu dan kemudian dihitung bobot masing-masing saham.

$$
Z_{\text {INCO }}=\frac{1}{(1-0,212333) 0,027093}[0,029386-0,013633]=0,740281
$$

Dari nilai keseluruhan investasi relatif masing-masing saham dijumlahkan dan didapatkan hasil untuk JII 2,867353, untuk LQ45 7.226582, dan INFOBANK15 10.532801. Dari nilai investasi relatif dan total akan dapat dihasilkan bobot masing-masing saham.

$$
X_{\text {INCO }}=\frac{0,740281}{2,867353}=0,258176 \text { atau } 25,8 \%
$$

Tabel 1. Bobot Masing-Masing Indeks

\begin{tabular}{ccccccc}
\hline No & JII & $\mathbf{X}_{\mathbf{i}}$ & LQ45 & $\mathbf{X}_{\mathbf{i}}$ & INFOBANK15 & $\mathbf{X}_{\mathbf{i}}$ \\
\hline 1 & INCO & 0,258176 & BRPT & 0,443701 & BBCA & 0,855701 \\
2 & PTBA & 0,231729 & BBCA & 0,509056 & BBRI & 0,144299 \\
3 & ANTM & 0,192000 & BBRI & 0,047243 & & \\
4 & ICBP & 0,318095 & & & & \\
\hline
\end{tabular}

- Expected Return dan Risiko Portofolio

Nilai expected return dan portofolio untuk masing-masing indeks saham adalah sebagai berikut.

Tabel 2. Expected Return, Risiko,

Indeks Expected Return Risiko




\begin{tabular}{ccc}
\hline JII & 0,000736 & 0,014739 \\
LQ45 & 0,001669 & 0,014190 \\
INFOBANK15 & 0,000906 & 0,011160 \\
\hline
\end{tabular}

\subsection{Kinerja Portofolio} berikut:

Perhitungan kinerja potofolio dengan rasio Sharpe menggunakan perhitungan sebagai

$$
I_{S}=\frac{0,000736-0,000145575}{0,014793}=0,040044
$$

Menghasilkan rasio Sharpe sebesar 0,040044 untuk indeks JII, 0,107341 untuk indeks LQ45, dan 0,065585 untuk INFOBANK15. Berdasarkan Tabel 2 dan hasil kinerja portofolio apabila investor akan menanamkan modalnya pada kelompok saham tertentu terdapat 3 pilihan dalam keputusannya. Investor yang ingin mendapatkan expected return yang tinggi maka akan disarankan mengambil portofolio indeks LQ45 dengan nilai sebesar $0.17 \%$. Apabila investor ingin mengambil portofolio dengan risiko yang minim maka disarankan untuk mengambil portofolio pada kelompok saham INFOBANK15 dengan nilai risiko sebesar $0,11 \%$. Keputusan ketiga apabila investor ingin mengambil nilai expected return terhadap risikonya atau kinerja portofolio disarankan untuk mengambil portofolio kelompok saham LQ45 dengan nilai kinerja portofolio sebesar 10,73\%.

\subsection{GUI MATLAB Constant Correlation Model}

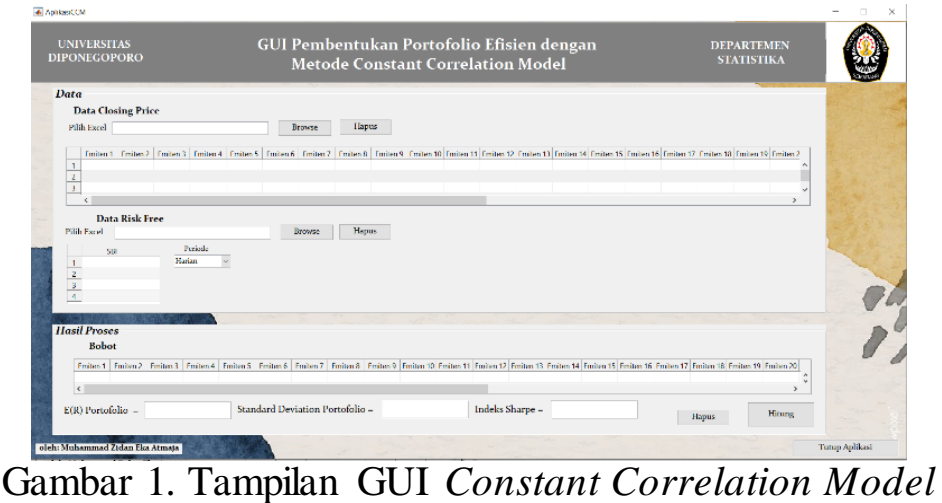

Untuk memudahkan end-user dalam memperoleh portofolio efisien dari beberapa emiten, perhitungan Constant Correlation Model dapat diperoleh melalui perhitungan program GUI Matlab. GUI Matlab yang dibentuk terbagi menjadi 3 panel, yaitu panel judul, panel data dan panel hasil proses. Panel judul mendeskripsikan keterangan dari metode yang digunakan dari GUI Matlab tersebut, panel data adalah panel yang harus diisikan dengan data-data yang diperlukan, dan panel hasil proses adalah panel yang menunjukkan hasil dari perhitungan GUI Matlab. Untuk data closing price dan risk free rate dimasukkan pada tabel yang sudah tersedia berdasarkan saham yang dipilih.

\section{KESIMPULAN}

Perhitungan pada portofolio pertama menghasilkan 4 emiten dari 18 emiten pada indeks JII. Emiten tersebut adalah ANTM, ICBP, INCO, dan PTBA. Menghasilkan expected return sebesar $0,07 \%$, risiko sebesar $1.47 \%$ dan kinerja portofolio sebesar $4,00 \%$. Perhitungan pada portofolio kedua menghasilkan 3 emiten dari 33 emiten pada indeks LQ45. Emiten tersebut 
adalah BBCA, BBRI, dan BRPT. Menghasilkan expected return sebesar $0,17 \%$, risiko sebesar $1.42 \%$ dan kinerja portofolio sebesar 10,73\%.Perhitungan pada portofolio ketiga menghasilkan 2 emiten dari 1 emiten pada indeks LQ45. Emiten tersebut adalah BBCA, dan BBRI. Menghasilkan expected return sebesar 0,09\%, risiko sebesar $1,12 \%$ dan kinerja portofolio sebesar $6,56 \%$.

Berdasarkan perhitungan telah dilakukan pada indeks JII, LQ45, dan INFOBANK15. Didapatkan 3 acuan bagi investor untuk melakukan keputusan investasi, apabila memprioritaskan nilai harapan pengembalian maka disarankan untuk saham pada LQ45. Apabila memprioritaskan risiko yang minim maka disarankan untuk saham pada INFOBANK15, dan untuk prioritas terhadap kinerja portofolio maka disarankan untuk mengambil saham pada LQ45.

\section{DAFTAR PUSTAKA}

Anoraga, P. \& Pakarti, P. 2001. Pengantar Pasar Modal. Jakarta: PT Rineka Cipta.

Darmadji, T. \& Fakhruddin, H. 2001. Pasar Modal di Indonesia. Jakarta: Salemba Empat.

Elton, E. \& Gruber, M. 1991. Modern Portfolio Theory and Investment Analysis. Canada: John Wiley \& Sons.

Fabozzi, F. 1999. Manajemen Investasi. Diterjemahkan oleh: Tim Penerjemah Salemba Empat.

Frade, C.A.Z. 2017. Performance Of Return Models: A PortfolioTeorical Approach. Disertasi. Lisboa. Instuto Superior de Economia e Gestāo.

Juniyanto, A. 2016. Analisis Portofolio Optimal Menggunakan Model Korelasi Konstan (Constant Correlation Model) (Studi Kasus: Saham Syariah di Jakarta Islamic Indeks (JII) Periode 27 Agustus 2014-26 Agustus 2015). Skripsi. Yogyakarta. Universitas Islam Negeri Sunan Kalijaga.

Hadi, N. 2013. Pasar Modal Acuan Teoritis dan Praktis Investasi di Instrumen Pasar Modal. Yogyakarta: Graha Ilmu.

Halim, A. 2003. Analisis Investasi. Jakarta : Salemba Empat.

Halim, A. 2015. Analisis Investasi di aset Keuangan. Jakarta: Mitra Wacana Media.

Hartono, J. 2014. Teori Portofolio dan Analisis Investasi. Edisi ke-9. Yogyakarta: BPFE.

Herlianto, D. 2013. Manajemen Investasi Plus Jurus Mendeteksi Investasi Bodong. Yogyakarta: Gosyen Publishing.

Jones, C.P. 2014. Investments Analysis and Management, 7th Edition. New York: John Wiley \& Sons, Inc.

Samsul, M. 2006. Pasar Modal dan Manajemen Portfolio. Jakarta: Erlangga.

Sucitra, A. Y., Yunita, I., \& Gustyanan, T. T. 2017. Analisis Portofolio Optimal Berdasarkan Metode Constant Correlation dan Penilaian Kinerja dengan Sharpe dan Treynor Measure. Openlibrary.telkomuniversity.ac.id.

Sugiyono. 2013. Metode Penlitian Pendidikan Pendekatan Kuantitatif, Kualitatif, dan R\&D. Bandung: Algabeta.

Tandelilin, E. 2001. Analisis Investasi dan Manajemen Portofolio. Yogyakarta: BPFE. Tjolleng, A. 2017. Pengantar Pemograman MATLAB. Jakarta: Kompas Gramedia. 